\title{
Journal of

\section{Strontium doping in mullite-type bismuth aluminate: a vacancy investigation using neutrons, photons and electrons}

\author{
Thorsten M. Gesing, ${ }^{* a b c}$ Marco Schowalter, ${ }^{d}$ Claudia Weidenthaler, ${ }^{e}$ M. Mangir Murshed, ${ }^{a}$ Gwilherm Nénert, ${ }^{f}$ \\ Cecilia B. Mendive, ${ }^{g}$ Mariano Curti, ${ }^{g}$ Andreas Rosenauer, ${ }^{d}$ J.-Christian Buhl, ${ }^{c}$ Hartmut Schneider ${ }^{b h}$ \\ and Reinhard X. Fischer ${ }^{b}$
}

Received 20th May 2012, Accepted 15th July 2012

DOI: $10.1039 / \mathrm{c} 2 \mathrm{jm} 33208 \mathrm{f}$

\begin{abstract}
We report on strontium doped dibismuth-nonaoxoaluminate(III) produced at $1023 \mathrm{~K}$. Partial substitution of bismuth by strontium in the structure yields oxygen vacancies for charge balance. Introducing oxygen vacancies rearranged the associated $\mathrm{Al}_{2} \mathrm{O}_{7}$ double-tetrahedra forming " $\mathrm{Al}_{3} \mathrm{O}_{10}$ " tri-clusters which were identified by multi-quantum ${ }^{27}$ Al MAS NMR. Both STEM-EDX and XPS showed homogeneous distribution of strontium in the bulk and on the surface, respectively. Moreover, XPS confirms the valence state of bismuth after doping. The orientations of bismuth $6 \mathrm{~s}^{2}$ lone electron pairs were calculated using DFT methods. The amount of strontium in the crystal structure was further confirmed from the decomposition product $\mathrm{SrAl}_{12} \mathrm{O}_{19}$ formed during the temperature-dependent X-ray powder diffraction. The structural proof was carried out by refining the structure of $\left(\mathrm{Bi}_{0.94} \mathrm{Sr}_{0.06}\right)_{2} \mathrm{Al}_{4} \mathrm{O}_{8.94}$ from powder neutron and $\mathrm{X}$-ray diffraction data. Rietveld refinements clearly showed the under occupation of one oxygen site and the shift of two aluminum atoms from the doubletetrahedra to two tri-cluster sites.
\end{abstract}

\section{Introduction}

For use in solid oxide fuel cells (SOFCs) it is desirable for electrolyte membranes to exhibit mechanical and chemical compatibility with the electrodes and the working environment, together with small membrane thicknesses $(L)$ and large areas $(A)$ to minimize $L / \sigma_{\mathrm{o}} A$ ( $\sigma_{\mathrm{o}}$ is the ion conductivity which should be greater than $1 \mathrm{~S} \mathrm{~m}^{-1}$ for reasonable performance at least at the operational temperature). ${ }^{1} \mathrm{With}$ respect to these criteria, bismuth containing phases like $\delta-\mathrm{Bi}_{2} \mathrm{O}_{3}$ (ref. 2) $\left(\sigma_{\mathrm{o}} \sim 23 \mathrm{~S} \mathrm{~m}^{-1}\right.$ at $\left.1073 \mathrm{~K}\right)$, Y-stabilized $\mathrm{Bi}_{1.5} \mathrm{Y}_{0.5} \mathrm{O}_{3}$ (ref. 2) $\left(\sigma_{\mathrm{o}} \sim 10 \mathrm{~S} \mathrm{~m}^{-1}\right.$ at $\left.1073 \mathrm{~K}\right)$, or metal stabilized $\mathrm{Bi}_{4} \mathrm{~V}_{2} \mathrm{O}_{11}$ Aurivillius phases (BIMEVOX) ${ }^{3}$ have been under discussion for years. The Aurivillius phases are built

${ }^{a}$ Chemische Kristallographie fester Stoffe, Universität Bremen, Leobener Straße/NW2, 28359 Bremen, Germany.E-mail: gesing@uni-bremen.de; Fax: +49421218 63145; Tel: +4942121863140

${ }^{b}$ Kristallographie, FB5 Geowissenschaften, Universität Bremen, Klagenfurter Straße, 28359 Bremen, Germany

${ }^{c}$ Kristallographie, Universität Hannover, Callinstraße 3, 30167 Hannover, Germany

${ }^{d}$ Festkörperphysik, Universität Bremen, Otto-Hahn-Alle/NW1, 28359 Bremen, Germany

${ }^{e}$ Max-Planck-Institut für Kohlenforschung, Kaiser-Wilhelm-Platz 1, 45470 Mülheim, Germany

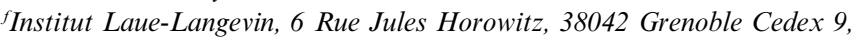
France

${ }^{g}$ Departamento de Química, Universidad Nacional de Mar del Plata, Dean Funes 3350, B7600A YL, Mar del Plata, Argentina

${ }^{h}$ Kristallographie, Universität Köln, Greinstraße 6, 50939 Köln, Germany of $\left(\mathrm{Bi}_{2} \mathrm{O}_{2}\right)^{2+}$ and perovskite-type $\left(\mathrm{VO}_{3.5}\right)^{2-}$ layers. In a similar manner the structure of $\mathrm{Bi}_{2} \mathrm{Al}_{4} \mathrm{O}_{9}$ (Fig. 1a) was described by Bloom et al $^{4}$ as possessing two different oxide sublattices of $\left(\mathrm{Bi}_{2} \mathrm{Al}_{2} \mathrm{O}_{5}\right)^{2+}$ and spinel type $\left(\mathrm{AlO}_{2}\right)^{-}$. This material showed a conductivity of $1 \mathrm{~S} \mathrm{~m}^{-1}$ at $1073 \mathrm{~K}$. $\mathrm{Bi}_{2} \mathrm{Al}_{4} \mathrm{O}_{9}$ (ref. 5 and 6) belongs to the family of mullite-type structures, ${ }^{7}$ which are characterized by one dimensional chains of edge sharing $\mathrm{MO}_{6}$ octahedra. $\mathrm{M}_{2} \mathrm{O}_{7}$ double tetrahedral units and $\mathrm{BiO}_{6} \mathrm{E}$ groups (where $\mathrm{E}$ refers to a $6 \mathrm{~s}^{2}$ lone electron pair (LEP)) interconnect the octahedral chains in $\mathrm{Bi}_{2} \mathrm{M}_{4} \mathrm{O}_{9}$ in an alternating ordered manner along the $c$-axis. This yields an additional possible oxygen position between two bismuth atoms. Nevertheless, this possible oxygen position is empty, giving enough space for a stereochemically active $\mathrm{Bi} 6 \mathrm{~s}^{2}$ LEP. Abrahams et al. ${ }^{8}$ proposed that these empty positions (voids) could be used by neighboring oxygen atoms as a jump position in a cooperative motion. However, a successful oxygen jump through this area (negative charge density area caused by the lone electron pairs) is only possible if the neighboring oxygen position is empty (Fig. 1b-d). An oxygen deficiency on this site, with the loss of an oxygen atom bridging the $\mathrm{Al}_{2} \mathrm{O}_{7}$ double tetrahedra, would dramatically increase the repulsive force between the two remaining aluminum cations. This mechanism possibly results in the movement of an $\mathrm{Al}^{3+}$ cation into the neighboring $\mathrm{Al}_{2} \mathrm{O}_{7} / \mathrm{BiO}_{6} \mathrm{E}$ chain. This leads to an $\mathrm{Al}^{*}$ position, forming $\mathrm{Al}_{3} \mathrm{O}_{10}$ tri-cluster of tetrahedra, which is well-known in mullite-type compounds. ${ }^{7}$ Larose and Akbar ${ }^{9}$ and Ohmann et al. ${ }^{10}$ carried out careful investigations on 
the conductivity of $\mathrm{Bi}_{2} \mathrm{Al}_{4} \mathrm{O}_{9}$ ceramic bodies over wide ranges of temperatures and oxygen partial pressures. They found only a low ionic conductivity that ruled out the possibility that the materials could be regarded as intrinsically defective fast ion conductors. The authors ${ }^{9}$ explained that the ion conductivity was almost exclusively due to the compensating oxygen vacancies related to impurities. Notably, the corresponding tri-cluster signals were not detected by the ${ }^{27} \mathrm{Al}$ MAS NMR spectroscopy carried out by Abrahams et al. ${ }^{8}$

To increase the number of oxygen vacancies in bismuth aluminates Zha et al. ${ }^{11}$ tried to partially replace bismuth by strontium. They found two transition temperature points in conductivity between $823 \mathrm{~K}$ and $873 \mathrm{~K}$ and between $973 \mathrm{~K}$ and $1023 \mathrm{~K}$. The conductivity for the $\left(\mathrm{Bi}_{1-x} \mathrm{Sr}_{x}\right)_{2} \mathrm{Al}_{4} \mathrm{O}_{9-x}$ samples was reported to increase with composition up to $x=0.1$, with a temperature-dependent conductivity behavior up to $x=0.2$. The samples ${ }^{11}$ used for the conductivity measurements were reported to be synthesized above $1323 \mathrm{~K}$. It is important to note that at this temperature all strontium-doped mullite-type bismuth aluminates are unstable. ${ }^{12}$ The decomposition probably led to (strontium-doped) $\mathrm{Bi}_{2} \mathrm{O}_{3}$ which showed phase transitions in the aforementioned temperature ranges. As reported by Ohmann et al. ${ }^{10} \delta-\mathrm{Bi}_{2} \mathrm{O}_{3}$ in the form of a thin film around the grains of the ternary oxide could increase the conductivity of a sample to the ranges reported by Zha et al. ${ }^{11}$ Incorporation of strontium into bismuth aluminate phases led to slight increases in all three orthorhombic lattice parameters. Due to the small lattice parameter deviations $(0.1-0.3 \mathrm{pm})$ between the un-doped and doped materials one can hardly decide from the evaluation of powder diffraction data whether strontium was incorporated into the crystal structure or not.

In this regard, clear-cut evidence was given on a $\left(\mathrm{Bi}_{1-x} \mathrm{Sr}_{x}\right)_{2} \mathrm{Al}_{4} \mathrm{O}_{9-x}$ sample synthesized with an initial concentration of $x=0.2$ using the glycerin method $^{12}$ in a detailed investigation. Here we address the following open questions of whether: (i) strontium is incorporated in the mullite-type bismuth aluminate structure; (ii) the structure compensates the charge while replacing $\mathrm{Bi}^{3+}$ with $\mathrm{Sr}^{2+}$; (iii) oxygen deficiency concentrates on the oxygen position bridging double tetrahedra which is the only one not involved in the mullite-type octahedral chains; and (iv) mullite-type tri-clusters are formed.

\section{Experimental}

\section{Synthesis}

Strontium-doped bismuth aluminate $\left(\mathrm{Bi}_{1-x} \mathrm{Sr}_{x}\right)_{2} \mathrm{Al}_{4} \mathrm{O}_{9-x}$, with a nominal concentration of $x=0.2$ was synthesized together with the parent bismuth aluminate $(x=0)$ by the glycerine method. Metal nitrates (hydrates) are weighted with respect to the stoichiometric needs and a small amount of glycerine was added as a solvent and reducing agent. This mixture was then heated at $350 \mathrm{~K}, 473 \mathrm{~K}$ and $1023 \mathrm{~K}$ for 30 minutes, $2 \mathrm{~h}$ and $24 \mathrm{~h}$, respectively (the synthesis method called normal). Further details of the glycerine method are available elsewhere. ${ }^{12}$ Additionally, a sample with $x=0.2$ was produced dropping the initial paste of well-mixed metal nitrates and glycerine into a crucible placed in a hot furnace $(1023 \mathrm{~K})$ to produce a sample with a large number of intrinsic defects and kept therein for two hours to burn out the

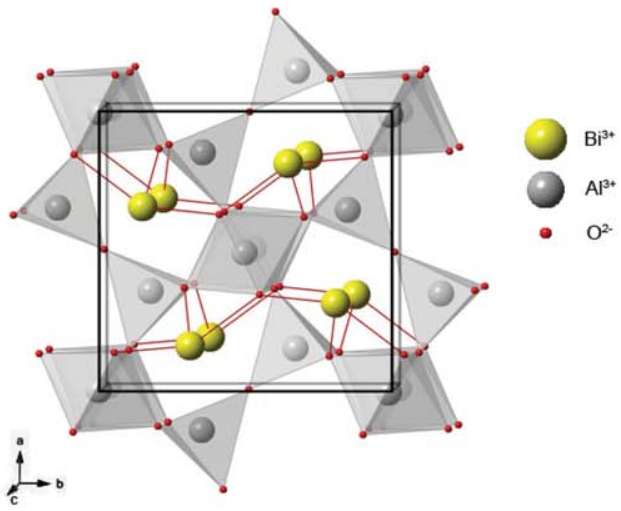

(a)

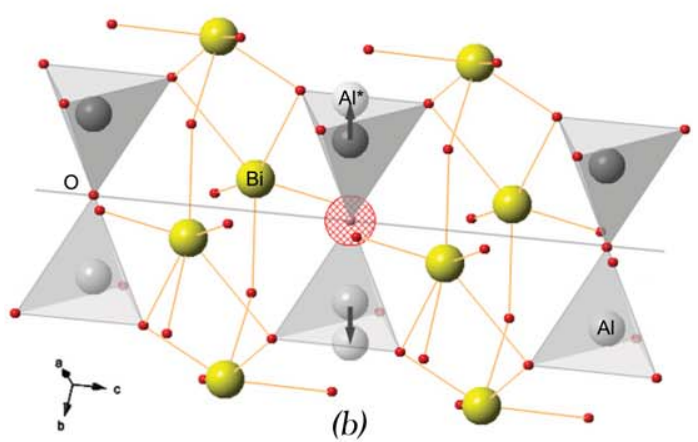

(b)

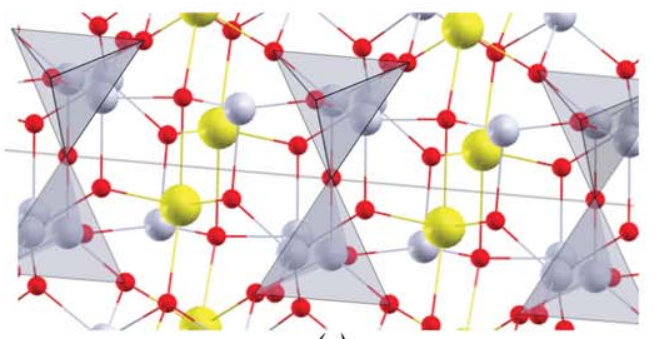

(c)

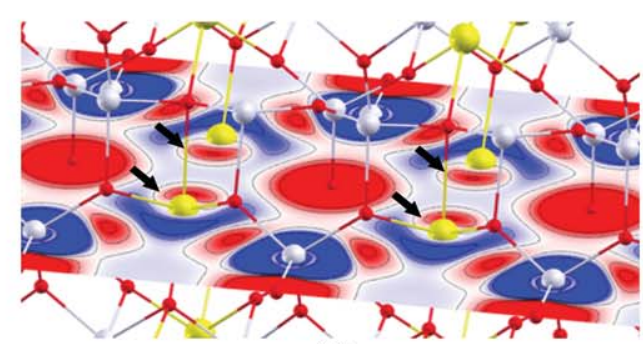

(d)

Fig. 1 (a) $\mathrm{The} \mathrm{Bi}_{2} \mathrm{Al}_{4} \mathrm{O}_{9}$ unit cell. (b) Schematic representation of one dimensional arrangement of $\mathrm{Al}_{2} \mathrm{O}_{7}$ double tetrahedral units and $\mathrm{BiO}_{6} \mathrm{E}$ groups parallel to the $c$-axis. The possible oxygen atom jump direction (solid line) is given together with the necessarily vacant oxygen position (red void) and the aluminum shift position $\left(\mathrm{Al}^{*}\right)$. (c) Optimized atomic positions (DFT calculations) showing the $\mathrm{Al}_{2} \mathrm{O}_{7}$ double tetrahedral units and $\mathrm{BiO}_{6} \mathrm{E}$ groups. The atomic radii have been arbitrarily chosen for visualization. (d) Calculated electronic densities at the plane containing the bismuth atoms showing the orientation of their LEPs (black arrows). The colour sequence blue-white-red corresponds to the increasing electronic charges respect to the neutral atoms in $e / 10^{6} \mathrm{pm}^{3}:-0.005,0.000$ and 0.005 . 
remaining carbon components (the synthesis method called fast). Both these samples were washed with $4 \mathrm{M} \mathrm{HNO}_{3}$ to remove impurities. Phase purity was checked using X-ray powder diffraction (collected at room temperature on a Panalytical X'Pert MPD diffractometer). Data were modeled using the Pawley method ${ }^{13}$ with the Diffrac ${ }^{\text {Plus }}$ Topas 4.2 program (Bruker AXS, Karlsruhe).

\section{TEM investigation}

TEM specimens were prepared by grinding the powder in ethanol and dispersing the particles onto a carbon film on top of a $\mathrm{Cu}$ grid. A FEI Titan 80-300 ST equipped with a corrector for the spherical aberration of the objective lens was operated at an acceleration voltage of $300 \mathrm{kV}$ for all TEM investigations. Conventional and high-resolution images were taken after alignment of the aberration corrector. For composition determinations, the microscope was switched to the scanning TEM (STEM) mode and an EDAX energy dispersive X-ray spectrometer was inserted. In the STEM mode a Fischione high angle annular dark field (HAADF) detector was used to record images and the electron probe was placed into particles for recording EDX spectra. The spectra were evaluated using the TIA software from FEI. High resolution gray-scale images were produced to clearly identify the particles to be analyzed. The different grayscale intensities perpendicular to the observed lattice fringes were transferred to a gray-scale vs. distance plot. The distances between the lattice fringes were fitted using the Diffrac ${ }^{\text {Plus }}$ Topas 4.2 program (Bruker AXS, Karlsruhe) and merged to get the lattice-plane distances. This distance was compared with the corresponding values calculated from the X-ray powder data Rietveld refinements. High resolution EDX analysis was carried out at several points on single particles. Additionally, the distribution of strontium within a single particle was analyzed across the vertical diameter.

\section{High temperature X-ray measurements}

The temperature-dependent X-ray powder experiments were performed on a PANalytical MPD powder diffractometer equipped with an Anton Paar-HTK1200N heating chamber using Bragg-Brentano geometry, a secondary Ni filter, $\mathrm{CuK} \alpha$ radiation and an X'Celerator detector. The finely grained powder was mixed with acetone, transferred to the corundum sample holder and mounted in the heating chamber after drying. Data collection was started at $298 \mathrm{~K}$ with steps of $50 \mathrm{~K}$ from 332 $\mathrm{K}$ to $1272 \mathrm{~K}$. Similar temperature steps $(50 \mathrm{~K})$ were followed during the cooling measurements down to room temperature. Some of the temperature-dependent X-ray runs were performed twice to check any further changes. For the description of the reflection profiles the fundamental parameter approach ${ }^{14}$ implemented in the refinement program Diffrac ${ }^{\text {Plus }}$ Topas was used. The instrument resolution was determined using a $\mathrm{LaB}_{6}$ standard powder for each configuration. A maximum of five background parameters (Chebychev function), scale factor and lattice parameters were refined together with the sample displacement parameter. The Lorentzian-Gaussian parameters were optimized for the calculation of the average crystal size $L_{\mathrm{Vol}}(\mathrm{IB})$ and the micro-strain $\varepsilon_{0}$.

\section{X-ray photoelectron spectroscopy}

XPS measurements were performed using a Kratos HSi spectrometer with a hemispherical analyzer. A monochromatic radiation $\mathrm{Al} \mathrm{K} \alpha \mathrm{X}$-ray source $(E=1486.6 \mathrm{eV})$ was operated at $15 \mathrm{kV}$ and $15 \mathrm{~mA}$. The hybrid mode was used as lens mode. The base pressure during the experiment in the analysis chamber was $4 \times 10^{-7} \mathrm{~Pa}$. To account for charging effects, all spectra have been referred to $\mathrm{C} 1 \mathrm{~s}$ at $284.5 \mathrm{eV}$. For the survey scans the photoelectron spectra in the energy range between zero and $1200 \mathrm{eV}$ were collected with an analyzer pass energy of $160 \mathrm{eV}$. For the regions of interest high-resolution scans were recorded with an analyzer pass energy of $40 \mathrm{eV}$, an energy step width of $0.1 \mathrm{eV}$ and 3 repetitions for each element.

\section{MAS NMR spectroscopy}

The ${ }^{27}$ Al MAS NMR spectra at 104.26 MHz were obtained using a standard $4 \mathrm{~mm}$ BRUKER MAS NMR probe in a Bruker ASX $400 \mathrm{WB}$ spectrometer. Typical conditions were a pulse length of $0.6 \mathrm{~ms}$ and a recycle delay of $100 \mathrm{~ms}$. A total of 30000 scans were accumulated at an MAS rotation frequency of $12.5 \mathrm{kHz}$. A $1.0 \mathrm{M}$ aqueous $\mathrm{Al}\left(\mathrm{NO}_{3}\right)_{3}$ solution was used as the reference standard. The ${ }^{27} \mathrm{Al}$ triple-quantum MAS NMR $\left({ }^{27} \mathrm{Al}\right.$ 3QMAS NMR) of the two-pulse experiment was performed using F2(TD) $=1024$ points, $\mathrm{SW}(\mathrm{F} 2)=50 \mathrm{kHz}, \mathrm{D} 1=200 \mathrm{~ms}, p 1=2$ microsecond, $p 2=1$ microsecond, $\mathrm{TD}(\mathrm{F} 1)=128$ points and $\mathrm{SW}(\mathrm{F} 1)=50$ $\mathrm{kHz}$. A total of 512 scans were accumulated with a recycle time of $200 \mathrm{~ms}$ at a MAS rotation frequency of $12.5 \mathrm{kHz}$.

\section{Powder neutron diffraction}

Neutron powder diffraction data were collected using the D2B high-resolution powder diffractometer at the Institut Laue Langevin in Grenoble, France. The measurements were carried out at a wavelength of $159.4 \mathrm{pm}$ corresponding to the (335) Bragg reflection of a germanium monochromator. The neutron detection was performed with ${ }^{3} \mathrm{He}$ counting tubes spaced at $1.25^{\circ}$ intervals (D2B) and a complete diffraction pattern was obtained after about 25 steps of $0.05^{\circ}$ in $2 \theta$. The measurements were carried out at room temperature in a vanadium container of $5 \mathrm{~mm}$ diameter. After the data collection, intensity data were extracted in two ways. First, only a narrow range in the middle of the 2D detector was used to obtain high-resolution data minimizing the curve of the Debye-Scherrer rings. Secondly, the whole detector range was evaluated resulting in less resolved data but with higher intensity. Both datasets were used for a combined refinement of the crystal structure, increasing the accuracy of the lattice parameters on one hand using the high-resolution data and the accuracy of the positional parameters on the other using the highintensity data. High-temperature data (not reported here) were measured using a furnace in which the sample was contained in a quartz tube in order to prevent any reaction of bismuth with the heating elements. Despite the fact that the quartz tube creates an additional and uneven background, the data at room temperature used here were also collected within the quartz tube.

\section{Density-functional theory calculations}

Periodic density-functional calculations were performed with the crystalline orbital program CRYSTAL09 ${ }^{15,16}$ employing Perdew 
and Wang (PW-GGA) ${ }^{17}$ exchange-correlation functions. The basis sets were taken from the CRYSTAL website. ${ }^{18}$ Electron density difference maps were calculated with a resolution of $5 \mathrm{pm}$, in order to identify the bismuth LEPs.

\section{Results and discussion}

\section{TEM investigation}

Synthesis of $\left(\mathrm{Bi}_{1-x} \mathrm{Sr}_{x}\right)_{2} \mathrm{Al}_{4} \mathrm{O}_{9-x}$ using the glycerine method ${ }^{12}$ led to materials with an average crystal size of approx. $300 \mathrm{~nm}$. EDX analysis in a scanning electron microscope on the powder samples clearly showed strontium signals. This observation leaves the question as to whether the strontium was incorporated into the crystal structure (bulk) or was concentrated mainly on the surface of the crystals. Therefore, the samples were investigated using a transmission electron microscope (TEM) giving a much higher resolution. A high-resolution image of a particle is shown in Fig. 2. In order to determine the lattice-plane distances the image was Fourier transformed and maxima positions were detected from the modulus of the Fourier transform. The distance from the center of the Fourier transform gives the reciprocal of the lattice-plane distance. The positions of the maxima were determined with a subpixel precision by computing the center of intensity within a small $7 \times 7$ pixel large region around the pixels with local maximum intensity. In order to estimate the precision of the lattice-plane distance, those distances corresponding to equivalent reflections have been averaged yielding standard deviations better than $0.4 \%$. For the particle in Fig. 2 we found distances of $592 \mathrm{pm}$ and $568 \mathrm{pm}$, and $407 \mathrm{pm}$ and $261 \mathrm{pm}$ for the reflections corresponding to the largest lattice-plane distance. We could find agreement with the nominal values of the lattice-plane distances. The above mentioned distances then correspond to the (001), (110), (111) and (112) lattice planes yielding the [1110] zone axis for this
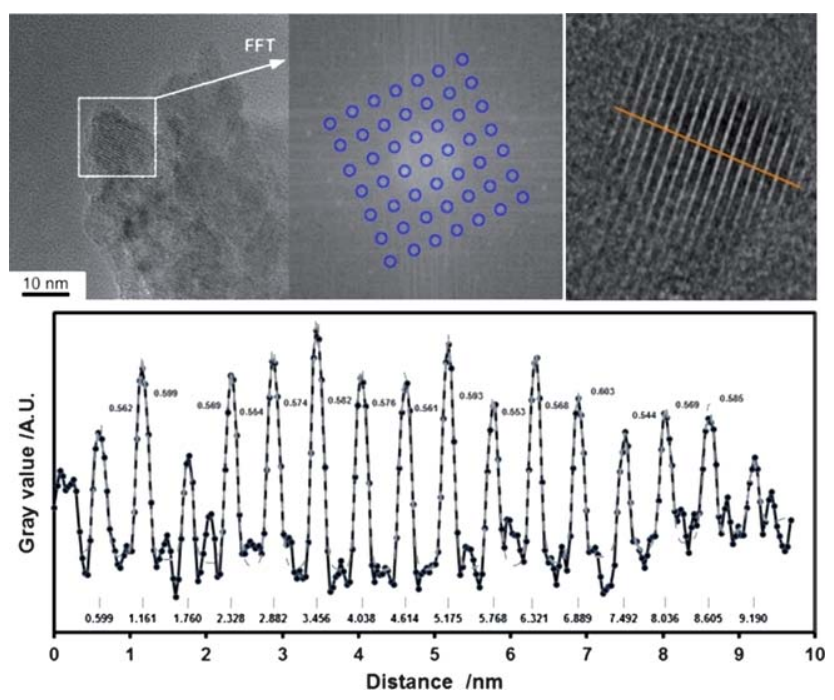

Fig. 2 High-resolution image including Fourier transformation, highresolution area (from left to right) and the corresponding gray value fit of lattice fringes (bottom) resulting in an average value for the lattice-plane distances of 572.7(173) pm. The corresponding $d$-value in X-ray powder data for the (001) plane is $568.96(2) \mathrm{pm}$.

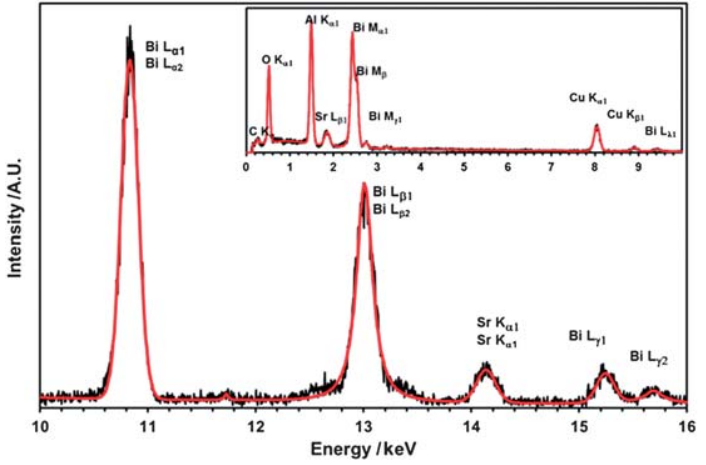

Fig. 3 EDX spectrum of strontium-doped bismuth aluminate collected with a spot size less than $0.3 \mathrm{~nm}$. Cu peaks are artifacts and caused by stray electrons exciting atoms of $\mathrm{Cu}$ grid.

particular particle. Additionally, gray-value curves of the highresolution TEM region (Fig. 2) were fitted, which led to reasonable distances between the lattice fringes from which the $d$-spacing of the corresponding lattice plane could be calculated by averaging. The calculated TEM $d$-spacings of $d_{001}=$ $572.7(173) \mathrm{pm}$ and $d_{021}=331.6(128) \mathrm{pm}$, for example, are in good agreement with the corresponding lattice-plane distances of $d_{001}=568.96(2) \mathrm{pm}$ and $d_{021}=330.00(3) \mathrm{pm}$, respectively, calculated from neutron powder data Rietveld refinements. The TEM-EDX spectra of some single particles (Fig. 3) clearly
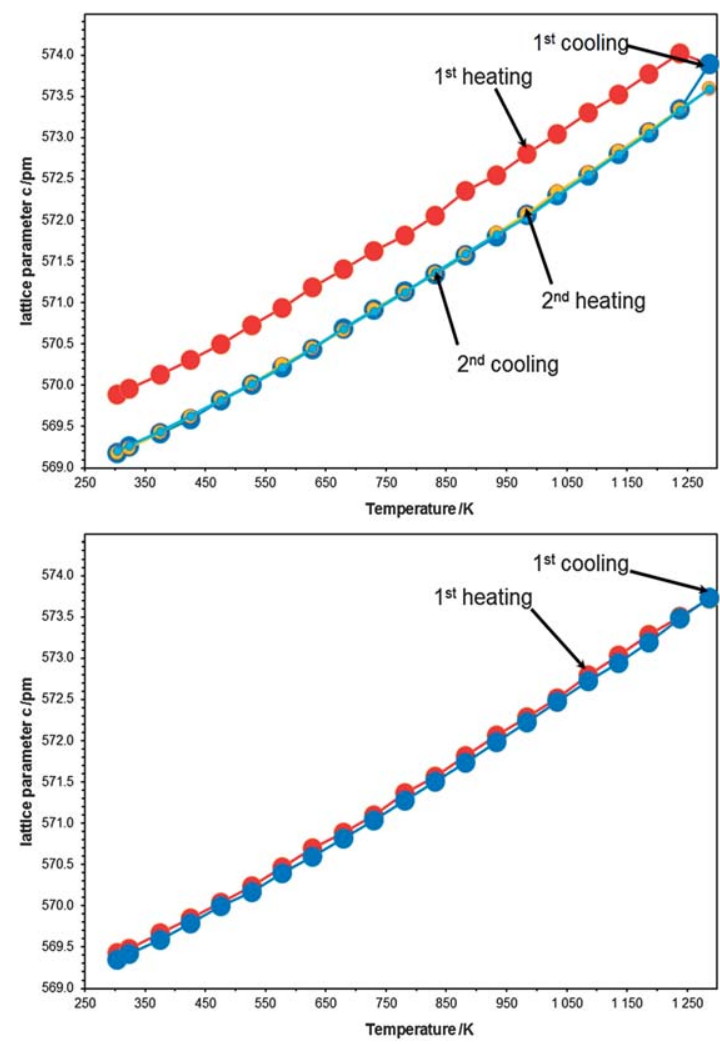

Fig. 4 Temperature-dependent $c$-lattice parameter change of strontiumdoped bismuth aluminate plotted for two temperature cycles (top) measured with the same sample and one corresponding temperature cycle of pure $\mathrm{Bi}_{2} \mathrm{Al}_{4} \mathrm{O}_{9}$ (bottom). 
Table 1 Binding energies (eV)

\begin{tabular}{|c|c|c|c|c|}
\hline & $\mathrm{Bi}_{2} \mathrm{O}_{3}$ & $\mathrm{Bi}_{2} \mathrm{Al}_{4} \mathrm{O}_{9}$ & $\begin{array}{c}\left(\mathrm{Bi}_{1-x} \mathrm{Sr}_{x}\right)_{2} \\
\mathrm{Al}_{4} \mathrm{O}_{9-x} \text { normal }\end{array}$ & $\begin{array}{c}\left(\mathrm{Bi}_{1-x} \mathrm{Sr}_{x}\right)_{2} \\
\mathrm{Al}_{4} \mathrm{O}_{9-x} \text { fast }\end{array}$ \\
\hline $\mathrm{Bi} 4 \mathrm{f}_{7 / 2}(\mathrm{I})^{a}$ & 158.2 & 158.5 & 158.5 & 158.5 \\
\hline $\mathrm{Bi} 4 \mathrm{f}_{5 / 2}(\mathrm{I})$ & 163.6 & 163.8 & 163.8 & 163.8 \\
\hline FWHM & 1.1 & 1.2 & 1.3 & 1.3 \\
\hline $\mathrm{Bi} 4 \mathrm{f}_{7 / 2}(\mathrm{II})$ & & & & 159.5 \\
\hline $\mathrm{Bi} 4 \mathrm{f}_{5 / 2}(\mathrm{II})$ & & & & 164.8 \\
\hline FWHM & & & & 1.3 \\
\hline $\operatorname{Sr} 3 d_{5 / 2}$ & & & 133.8 & 133.0 \\
\hline $\operatorname{Sr} 3 d_{3 / 2}$ & & & 135.6 & 134.8 \\
\hline FWHM & & & 2.1 & 1.8 \\
\hline $\mathrm{Al} 2 \mathrm{p}(\mathrm{I})$ & & 73.0 & 73.0 & 73.1 \\
\hline Al 2p(II) & & 74.0 & 73.9 & 74.2 \\
\hline FWHM & & 1.2 & 1.3 & 1.4 \\
\hline O 1s(I) & 528.9 & 529.5 & 529.5 & 529.5 \\
\hline O 1s(II) & 530.2 & 530.9 & 531.0 & 531.0 \\
\hline O 1s(III) & 531.1 & 532.0 & 532.1 & 532.1 \\
\hline FWHM & 1.1 & 1.4 & 1.3 & 1.5 \\
\hline
\end{tabular}

${ }^{a}$ Different species are marked with (I), (II), and (III).

showed the existence of strontium in the bulk of the crystal, best seen on the $\mathrm{Sr} \mathrm{K} \alpha$ emission line at 14.14(2) $\mathrm{keV}$. A careful evaluation of the STEM-EDX spectra led to an $\mathrm{Al} /(\mathrm{Bi}+\mathrm{Sr})$ ratio of 2.00(2) which is in excellent agreement with the chemical formula $\left(\mathrm{Bi}_{1-x} \mathrm{Sr}_{x}\right)_{2} \mathrm{Al}_{4} \mathrm{O}_{9-x}$. The average $\mathrm{Sr} / \mathrm{Bi}$ ratio was obtained as $0.06(1)$ with a variation between $x=0.04$ and $x=$ 0.07. This scattering can be interpreted in terms of inhomogeneity of the chemical constituents in different particles. However, an analytical variation (standard deviation) cannot be excluded. The observed $\mathrm{Cu}$ peaks can be considered as artifacts due to stray electrons hitting the $\mathrm{Cu}$ grid. The strontium distribution across a particle was further checked using linear scans. Within the error of our measurements the elements are homogeneously distributed. Quantitative evaluation of the spectra taken during the scans led to small deviations from the stoichiometric composition. This can be attributed to the relatively low number of counts. Note that the beam current could not be increased without risking damage to the particle. The absolute intensity of the $\mathrm{Bi}-\mathrm{L}, \mathrm{Al}-\mathrm{K}$ and $\mathrm{Sr}-\mathrm{K}$ lines, which were used for the analysis, follow in the same manner the thickness of the investigated particle corresponding to $\left(\mathrm{Bi}_{0.95(2)} \mathrm{Sr}_{0.05(2)}\right)_{2} \mathrm{Al}_{4.00(4)} \mathrm{O}_{8.95(2)}$. The oxygen content given here was calculated on the basis of the cation charge compensation, but corresponds (with a higher error) to the analyzed values. We conclude here that the investigated sample is more or less homogeneous, with a strontium content of $x=0.06(2)$.

\section{High-temperature X-ray powder diffraction}

The room-temperature $\mathrm{X}$-ray powder data can be indexed as a single $\left(\mathrm{Bi}_{1-x} \mathrm{Sr}_{x}\right)_{2} \mathrm{Al}_{4} \mathrm{O}_{9-x}$ phase with the following crystallographic parameters: $a=772.12(1) \mathrm{pm}, b=812.04(1) \mathrm{pm}, c=$ $569.89(1) \mathrm{pm}$ and $V=357.32(3) \times 10^{6} \mathrm{pm}^{3}$. The lattice parameters of the normal sample increase with temperature as shown in Fig. 4 with thermal expansion coefficients of 5.24(2) $\times 10^{-6} \mathrm{~K}^{-1}$, $8.96(2) \times 10^{-6} \mathrm{~K}^{-1}, 7.69(3) \times 10^{-6} \mathrm{~K}^{-1}$ and $22.0(1) \times 10^{-6} \mathrm{~K}^{-1}$ for $(\Delta a / a) / \Delta T,(\Delta b / b) / \Delta T,(\Delta c / c) / \Delta T$ and $(\Delta V / V) / \Delta T$, respectively, between $298 \mathrm{~K}$ and $1173 \mathrm{~K}$. Above $1235 \mathrm{~K}$ all three lattice parameters decrease accompanied by the formation of $\mathrm{SrAl}_{12} \mathrm{O}_{19}$ (hibonite). After cooling the sample back to room temperature (Fig. 4) the lattice parameters were found to be $a=771.76(1) \mathrm{pm}$, $b=811.39(1) \mathrm{pm}, c=569.21(1) \mathrm{pm}$ and $V=356.43(3) \times 10^{-6}$ $\mathrm{pm}^{3}$. These lattice parameters were further investigated in a second heating/cooling cycle. No hysteresis was observed. For the second cycle the calculated thermal expansion coefficients were $5.31(2) \times 10^{-6} \mathrm{~K}^{-1}, 9.17(2) \times 10^{-6} \mathrm{~K}^{-1}, 7.70(3) \times 10^{-6}$ $\mathrm{K}^{-1}$ and $22.3(1) \times 10^{-6} \mathrm{~K}^{-1}$ for $(\Delta a / a) / \Delta T,(\Delta b / b) / \Delta T,(\Delta c / c) / \Delta T$ and $(\Delta V / V) / \Delta T$, respectively, between $300 \mathrm{~K}$ and $1273 \mathrm{~K}$. Whereas no deviation in the lattice parameters was observed, as was also found for pure $\mathrm{Bi}_{2} \mathrm{Al}_{4} \mathrm{O}_{9}$ (Fig. 4), the thermal expansion coefficients were slightly smaller than those of the undoped material, showing 5.53(6) $\times 10^{-6} \mathrm{~K}^{-1}, 9.45(2) \times 10^{-6} \mathrm{~K}^{-1}$, $7.80(8) \times 10^{-6} \mathrm{~K}^{-1}$ and $22.9(2) \times 10^{-6} \mathrm{~K}^{-1}$ for $(\Delta a / a) / \Delta T$, $(\Delta b / b) / \Delta T,(\Delta c / c) / \Delta T$ and $(\Delta V / V) / \Delta T$, respectively. Therefore, it is likely that the thermal expansion of the strontium-doped
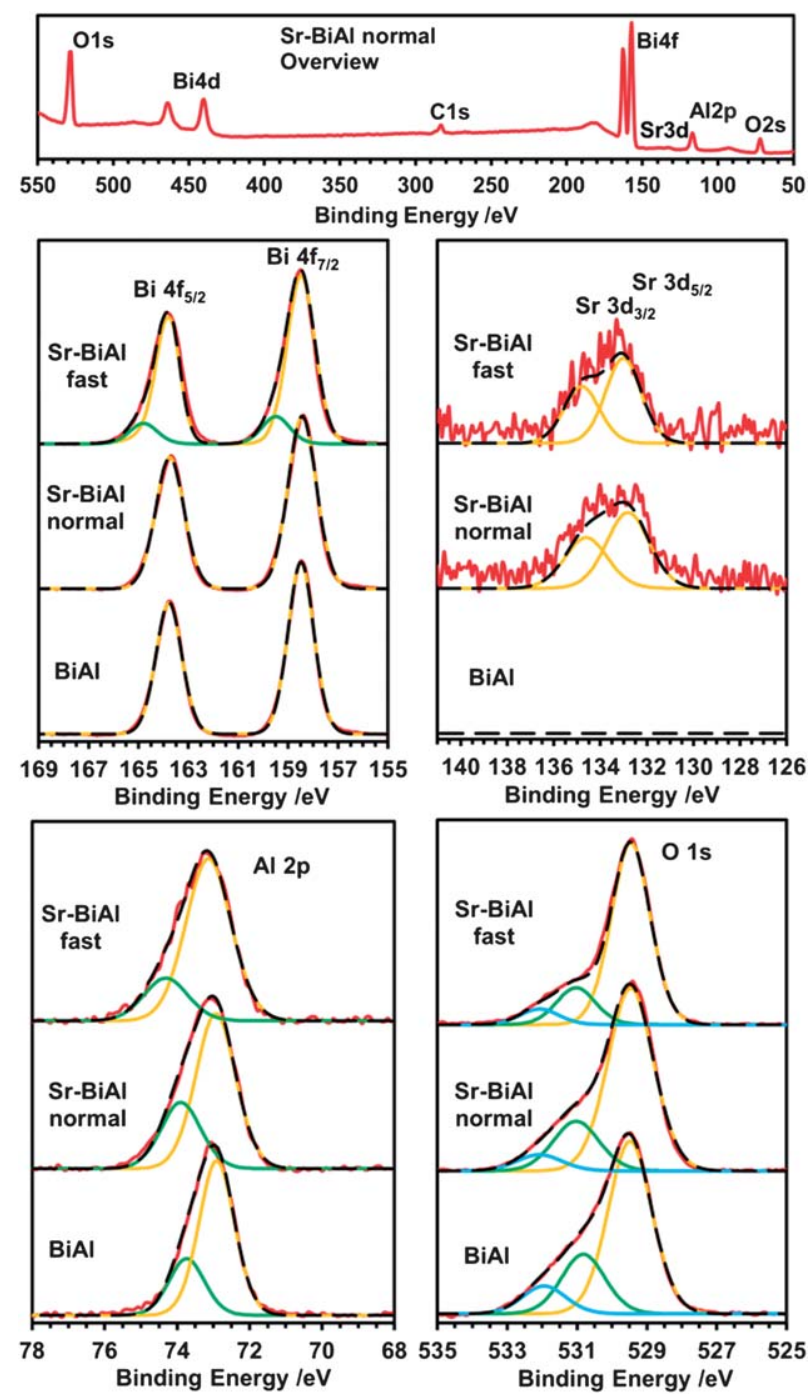

Fig. 5 X-ray photoelectron overview spectrum (top) and high-resolution spectra of $\mathrm{O} 1 \mathrm{~s}, \mathrm{Bi} 4 \mathrm{f}, \mathrm{Sr} 3 \mathrm{~d}$, and $\mathrm{Al} 2 \mathrm{p}$ of pure $\mathrm{Bi}_{2} \mathrm{Al}_{4} \mathrm{O}_{9}(\mathrm{BiAl})$, $\left(\mathrm{Bi}_{1-x} \mathrm{Sr}_{x}\right)_{2} \mathrm{Al}_{4} \mathrm{O}_{9-x}$ normally synthesized ( $\mathrm{Sr}-\mathrm{BiAl}$ normal) and fast synthesized ( $\mathrm{Sr}-\mathrm{BiAl}$ fast) together with the fit results (interrupted line) and the single peaks. 
material was influenced by the decomposition of the phase into $\mathrm{Bi}_{2} \mathrm{Al}_{4} \mathrm{O}_{9}, \mathrm{SrAl}_{12} \mathrm{O}_{19}$ and $\mathrm{Bi}_{2} \mathrm{O}_{3}$. The latter was first observed while cooling between $1123 \mathrm{~K}$ and $1073 \mathrm{~K}$ forming the $\delta$-phase. The phase transitions to the $\beta$-phase and at lower temperatures to the $\alpha$-phase could not be observed at the reported temperatures of $920 \mathrm{~K}$ and $603 \mathrm{~K},{ }^{19}$ respectively.

The $\delta>\beta$ transition was found at somewhat lower temperatures whereas the $\beta>\alpha$ transition could not be clearly demonstrated. This might be a hint that small amounts of strontium were incorporated into the binary bismuthoxide, as also proposed by Ohmann et al. ${ }^{10}$ which must be taken into account when calculating the strontium content in $\left(\mathrm{Bi}_{1-x} \mathrm{Sr}_{x}\right)_{2} \mathrm{Al}_{4} \mathrm{O}_{9-x}$ after the decomposition. Nevertheless, assuming that the initial $\left(\mathrm{Bi}_{1-x} \mathrm{Sr}_{x}\right)_{2} \mathrm{Al}_{4} \mathrm{O}_{9-x}$ lost all the strontium that was transferred into the crystalline $\mathrm{SrAl}_{12} \mathrm{O}_{19}$ during the decomposition, a strontium content of $x=0.05(3)$ could be calculated. This value might be slightly higher because of the possible incorporation of strontium into $\mathrm{Bi}_{2} \mathrm{O}_{3}$ or some non-crystalline $\mathrm{X}$-ray amorphous residues.

The fast synthesized strontium-doped sample showed similar lattice expansion at high temperatures. For this sample a somewhat higher diffuse scattering originated in disordered regions of the sample (showing a short translation length) was observed. The room-temperature lattice parameters $a=772.27(1) /$ 771.88(1) pm, $b=811.86(1) / 811.11(1) \mathrm{pm}, c=569.99(1) /$ $569.13(1) \mathrm{pm}$ and $V=357.37(3) / 356.32(3) \times 10^{-6} \mathrm{pm}^{3}$ were observed before/after the measuring cycle, respectively. The average thermal expansion coefficients of $5.2(2) \times 10^{-6} \mathrm{~K}^{-1}$, $9.2(3) \times 10^{-6} \mathrm{~K}^{-1}, 7.4(7) \times 10^{-6} \mathrm{~K}^{-1}$ and $22(1) \times 10^{-6} \mathrm{~K}^{-1}$ for $(\Delta a / a) / \Delta T,(\Delta b / b) / \Delta T,(\Delta c / c) / \Delta T$ and $(\Delta V / V) / \Delta T$, respectively, were calculated between $298 \mathrm{~K}$ and $1173 \mathrm{~K}$ over two cycles.

\section{XPS investigation}

XPS was used to compare the oxidation state of bismuth in the strontium-doped and undoped samples synthesized normally and fast. The relation between $\mathrm{Al}$ and $(\mathrm{Bi}+\mathrm{Sr})$ on one hand and between $\mathrm{Bi}$ and $\mathrm{Sr}$ on the other gives evidence as to which metal is enriched in the terminating crystal layers and also on the concentration of strontium on the surface. The latter clearly showed with respect to the results of the TEM/EDX investigations whether strontium is homogeneously distributed within the crystallites or enriched on the surface. The Bi/Al mole ratio in pure $\mathrm{Bi}_{2} \mathrm{Al}_{4} \mathrm{O}_{9}$, calculated from high-resolution scans, was found to be $30(1) / 70(1)=0.43(2)$. Compared with the formula ratio of 0.5 the aluminum concentration is enriched on the surface, indicating that a terminating aluminum-oxygen layer at the surface is more probable than the corresponding bismuthoxygen layer. As expected, only one $4 \mathrm{f}_{5 / 2} / 4 \mathrm{f}_{7 / 2}$ doublet, as given in Table 1 and shown in Fig. 5, at $163.8 \mathrm{eV} / 158.5 \mathrm{eV}$ was found in the high-resolution scan for the bismuth signals comparable to $163.6 \mathrm{eV} / 158.2 \mathrm{eV}$ for $\mathrm{Bi}^{3+}$ in $\alpha-\mathrm{Bi}_{2} \mathrm{O}_{3}$, which was additionally measured as a reference. For the normally synthesized strontiumdoped bismuth aluminate $\left(\mathrm{Bi}_{1-x} \mathrm{Sr}_{x}\right)_{2} \mathrm{Al}_{4} \mathrm{O}_{9-x}$ the $\mathrm{Bi}^{3+} 4 \mathrm{f}_{5 / 2} / 4 \mathrm{f}_{7 / 2}$ doublet was found at $163.8 \mathrm{eV} / 158.5 \mathrm{eV}$. This is in good agreement with the signal fitted to the undoped material, where there is again only one $\mathrm{Bi}^{3+}$ doublet, confirming that no deviation from the plus three oxidation state occurs. Additionally, strontium was clearly detected in the XPS spectrum of this compound and the evaluation of the high-resolution scans gives $24(1)$ at $\% \mathrm{Bi}$, 1(1) at $\% \mathrm{Sr}$ and $75 \mathrm{at} \% \mathrm{Al}$. This yields a $\mathrm{Sr} / \mathrm{Bi}$ ratio of $0.04(4)$ and $\mathrm{a}(\mathrm{Bi}+\mathrm{Sr}) / \mathrm{Al}$ ratio of $0.33(2)$.

The first result demonstrated the incorporation of strontium into the structure in a range comparable to that of values found in the TEM/EDX investigations. The second ratio gave evidence of strontium in the bulk rather than surface enrichment. It is reasonable to assume that the termination of the surface with aluminum in the doped sample is more pronounced than that of the undoped phase. Such behavior leads to a higher strain in the structure introduced by the replacement of bismuth by strontium and to a higher exsolution of the observed areas in the surface.

A similar situation was observed for the fast synthesized strontium-doped compound. 27(1) at $\% \mathrm{Bi}, 1(1)$ at $\% \mathrm{Sr}$ and 72 at $\% \mathrm{Al}$ were analyzed giving a $\mathrm{Sr} / \mathrm{Bi}$ ratio of $0.04(4)$ (slightly lower than that of the normally synthesized sample, although the relation factor is mathematically similar) and a $(\mathrm{Bi}+\mathrm{Sr}) / \mathrm{Al}$ ratio of 0.39 (2). In contrast to the normally synthesized sample, two separate signals were found for the $\mathrm{Bi} 4 \mathrm{f}_{5 / 2} / 4 \mathrm{f}_{7 / 2}$ doublet. The first one at $163.8 \mathrm{eV} / 158.5 \mathrm{eV}$ corresponds well to the $\mathrm{Bi}^{3+}$ signals in other related compounds. The second signal at $164.8 \mathrm{eV} / 159.5 \mathrm{eV}$ (Fig. 5) has a calculated intensity ratio of 0.15 (2) for the $4 \mathrm{f}_{7 / 2}$ binding energy peaks at $159.5 \mathrm{eV}$ and $158.5 \mathrm{eV}$, respectively. $\mathrm{Bi}^{5+}$ shows a $4 \mathrm{f}_{7 / 2}$ binding energy peak at $160.4 \mathrm{eV} \cdot{ }^{20} \mathrm{Bi}^{4+}$ might be possible, but its presence is probably unrealistic in these compounds. Most probably, the $4 \mathrm{f}_{7 / 2}$ binding energy peak at 159.51(2) eV corresponds to a second $\mathrm{Bi}^{3+}$ state in this compound. The other possibility of a second phase with a different oxygen coordination of the bismuth was not observed so far, thus must be ruled out. A likely explanation is that some of the bismuth atoms ( $\mathrm{ca} .15 \%)$ are in highly distorted coordination environments due to a large number of intrinsic defects associated with the fast synthesis of this material. For local charge compensation the remaining oxygen bonds of the bismuth atoms suffering from this defect coordination must be shortened

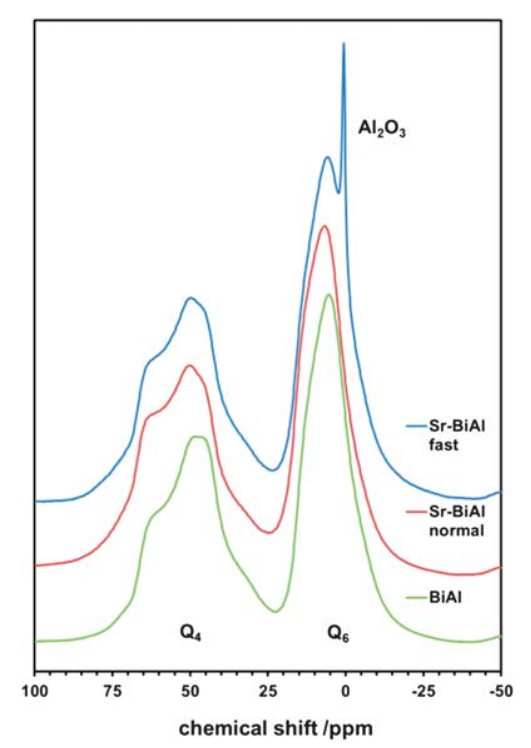

Fig. $6{ }^{27} \mathrm{MAS}$ NMR spectra of pure $\mathrm{Bi}_{2} \mathrm{Al}_{4} \mathrm{O}_{9} \quad(\mathrm{BiAl})$ and $\left(\mathrm{Bi}_{1-x} \mathrm{Sr}_{x}\right)_{2} \mathrm{Al}_{4} \mathrm{O}_{9-x}$ normally and fast synthesized ( $\left.\mathrm{Sr}-\mathrm{BiAl}\right)$. 

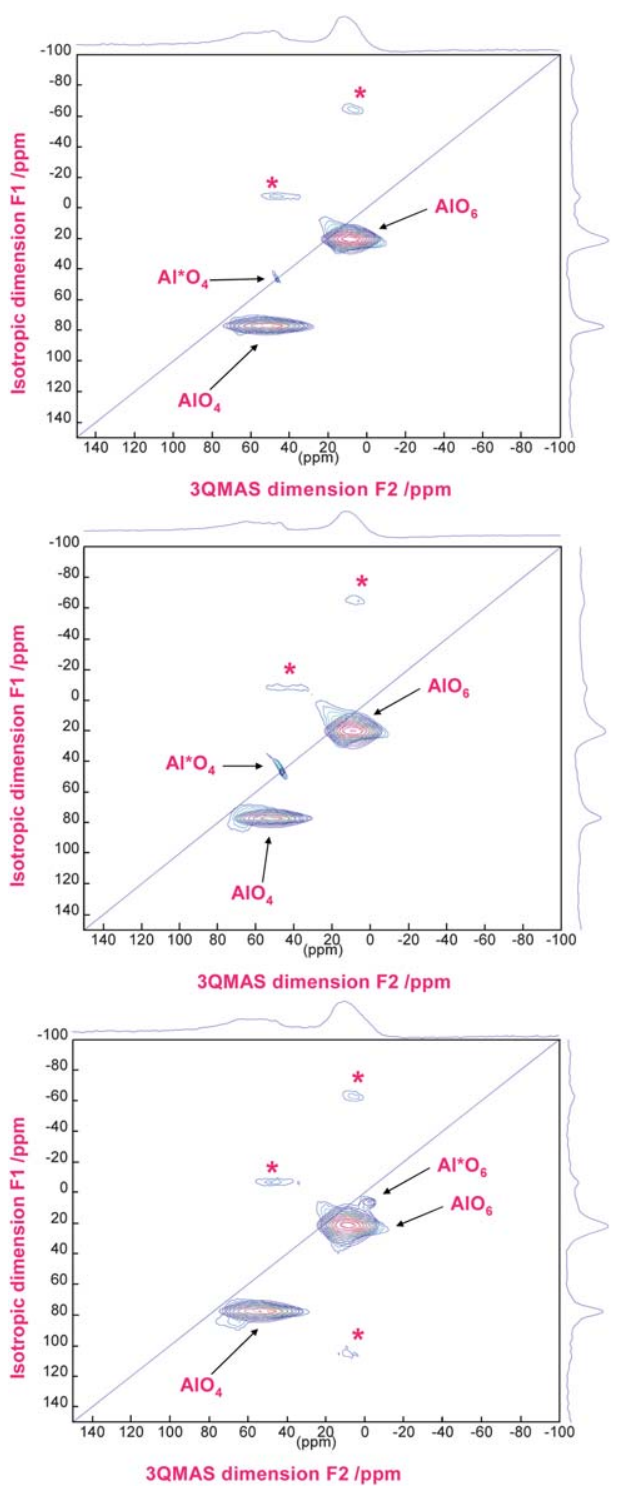

Fig. 7 Simulation of the MQMAS of pure $\mathrm{Bi}_{2} \mathrm{Al}_{4} \mathrm{O}_{9}$ (top), $\left(\mathrm{Bi}_{1-x} \mathrm{Sr}_{x}\right)_{2} \mathrm{Al}_{4} \mathrm{O}_{9-x}$ normally synthesized (middle) and fast synthesized (bottom) on the basis of the measured data. Simulations take into account the central $\langle-1 / 2 \leftrightarrow 1 / 2\rangle$ transition; the related spinning sidebands of the external $\langle \pm 1 / 2 \leftrightarrow \pm 3 / 2\rangle$ transitions have not been considered and are shown by asterisks.

which leads to an increasing average binding energy for these $\mathrm{Bi}^{3+}$ atoms.

\section{NMR investigation}

The inherent complication of ${ }^{27} \mathrm{Al}$ MAS NMR is the second order quadrupolar interaction of the central transition. As a result, resonances move from their isotropic chemical shift to the quadrupolar induced shift and broaden into specific powder line shapes even under MAS conditions. Hence, the ${ }^{27}$ Al MAS NMR spectra (Fig. 6) may consist of resonances shifted with respect to their isotropic chemical shifts, which are not well-resolved, and some species of interest may escape detection due to extreme broadening. Therefore, care must be taken when interpreting the
${ }^{27}$ Al MAS NMR spectra. To avoid such broadening complications, triple quantum (3Q) MAS NMR provides determination of isotropic chemical shifts with an unambiguous assignment of the nuclei with $>1 / 2$ spins such as aluminum $(5 / 2$ spin). The 3QMAS NMR experiment correlates between the multiple and single quantum transitions, which leads to well-resolved spectra that have an isotropic dimension, free of any anisotropic quadrupolar broadening. Therefore this technique permits the determination of the aluminum coordinations in the sample, and a simulation of the 3QMAS NMR spectra (Fig. 7) provides the NMR parameters and their distributions (Table 2). Of particular note, sometimes the 3QMAS experiment is intrinsically not quantitative, and it is necessary to perform a careful simulation to extract the population of the aluminum species. The 3QMAS experiment requires both high magnetic field and high speed sample rotation for a good resolved spectrum.

In the strontium-doped fast synthesized sample three peaks close to the diagonal line were observed which refer to aluminum species. The peak at $0.6 \mathrm{ppm}$ (Table 2) has been assigned to $\mathrm{AlO}_{6}$, which is also clear in the MAS NMR spectrum (Fig. 6), most probably originating from (X-ray amorphous) $\mathrm{Al}_{2} \mathrm{O}_{3}$ residues in the sample. However, there is an ambiguity in the intensity of this peak between the 3QMAS NMR and MAS NMR experiments. This signal seems to be close to the signal usually observed for non-framework $\mathrm{AlO}_{6}$ species. The signals at 17.9(5) ppm $\left(\mathrm{AlO}_{6}\right)$ and $71.7(5) \mathrm{ppm}\left(\mathrm{AlO}_{4}\right)$ could be assigned to the mullite-type phase. Their position correlated quite well with the corresponding one of the pure $\mathrm{Bi}_{2} \mathrm{Al}_{4} \mathrm{O}_{9}$ at $17.5(5) \mathrm{ppm}\left(\mathrm{Q}_{6}\right)$ and $69.6(5) \mathrm{ppm}$ $\left(\mathrm{Q}_{4}\right)$. In the normally synthesized strontium doped sample these signals were found to be somewhat more shifted at $18.6(5) \mathrm{ppm}$ $\left(Q_{6}\right)$ and 74.5(5) ppm $\left(Q_{4}\right)$ indicating a slightly different arrangement of the polyhedra. Additionally, a third signal of lower intensity was found at 46.8(5) ppm. Besides the conventional $\mathrm{AlO}_{4}$ species, this signal can be assigned to $\mathrm{Al}^{*} \mathrm{O}_{4}$ units in tri-clusters. Surprisingly such a signal was also found in the undoped material at 46.8(5) ppm with a very low intensity indicating also the existence of tri-clusters in pure $\mathrm{Bi}_{2} \mathrm{Al}_{4} \mathrm{O}_{9}$. On the

Table 2 Isotropic chemical shift ( $\delta_{\text {iso }}$ ), quadrupolar coupling constant $\left(C_{\mathrm{Q}}\right)$ and asymmetry parameter $\left(\eta_{\mathrm{Q}}\right)$ of ${ }^{27} \mathrm{Al} 3 \mathrm{MQMAS}$ and MAS NMR spectra calculated from iterative simulation

\begin{tabular}{|c|c|c|c|c|c|}
\hline Sample & NMR & Coord. & $\begin{array}{l}\delta_{\text {iso }} / \mathrm{ppm} \\
( \pm 0.5)\end{array}$ & $\begin{array}{l}C_{\mathrm{Q}} / \mathrm{MHz} \\
( \pm 0.02)\end{array}$ & $\begin{array}{c}\eta_{\mathrm{Q}} \\
( \pm 0.1)\end{array}$ \\
\hline \multirow{6}{*}{$\begin{array}{l}\text { Sr doped } \\
\text { fast synthesis }\end{array}$} & \multirow[t]{3}{*}{ 3QMAS } & $\mathrm{AlO}_{6}$ & 4.3 & 3.4 & 0.40 \\
\hline & & $\mathrm{AlO}_{6}$ & 16.8 & 3.8 & 0.66 \\
\hline & & $\mathrm{AlO}_{4}$ & 67.8 & 5.1 & 0.67 \\
\hline & \multirow[t]{3}{*}{ MAS } & $\mathrm{AlO}_{6}$ & 0.6 & - & - \\
\hline & & $\mathrm{AlO}_{6}$ & 17.9 & 4.6 & 0.55 \\
\hline & & $\mathrm{AlO}_{4}$ & 71.7 & 5.8 & 0.64 \\
\hline \multirow{6}{*}{$\begin{array}{l}\text { Sr doped } \\
\text { normal synthesis }\end{array}$} & \multirow[t]{3}{*}{ 3QMAS } & $\mathrm{AlO}_{6}$ & 16.2 & 3.3 & 0.66 \\
\hline & & $\mathrm{AlO}_{4}$ & 67.2 & 5.0 & 0.67 \\
\hline & & $\mathrm{Al}^{*} \mathrm{O}_{4}$ & 46.8 & - & - \\
\hline & \multirow[t]{3}{*}{ MAS } & $\mathrm{AlO}_{6}$ & 18.6 & 4.4 & 0.58 \\
\hline & & $\mathrm{AlO}_{4}$ & 74.5 & 6.0 & 0.69 \\
\hline & & $\mathrm{Al}^{*} \mathrm{O}_{4}$ & - & - & - \\
\hline \multirow{6}{*}{ Pure $\mathrm{Bi}_{2} \mathrm{Al}_{4} \mathrm{O}_{9}$} & \multirow{3}{*}{ 3QMAS } & $\mathrm{AlO}_{6}$ & 16.2 & 3.6 & 0.66 \\
\hline & & $\mathrm{AlO}_{4}$ & 66.9 & 5.2 & 0.72 \\
\hline & & $\mathrm{Al}^{*} \mathrm{O}_{4}$ & 46.8 & - & - \\
\hline & \multirow{3}{*}{ MAS } & $\mathrm{AlO}_{6}$ & 17.5 & 4.4 & 0.59 \\
\hline & & $\mathrm{AlO}_{4}$ & 69.6 & 5.7 & 0.69 \\
\hline & & $\mathrm{Al}^{*} \mathrm{O}_{4}$ & - & - & - \\
\hline
\end{tabular}


Table 3 Position parameters of $\left(\mathrm{Bi}_{0.94(1)} \mathrm{Sr}_{0.06(1)}\right)_{2} \mathrm{Al}_{4} \mathrm{O}_{8.94(1)}$ refined from $298 \mathrm{~K}$ powder neutron diffraction data $($ Pbam: $a=771.25(3)$ pm, $b=$ $\left.810.18(3) \mathrm{pm}, c=568.96(2) \mathrm{pm}, V=355.52(2) \times 10^{6} \mathrm{pm}^{3}\right)$

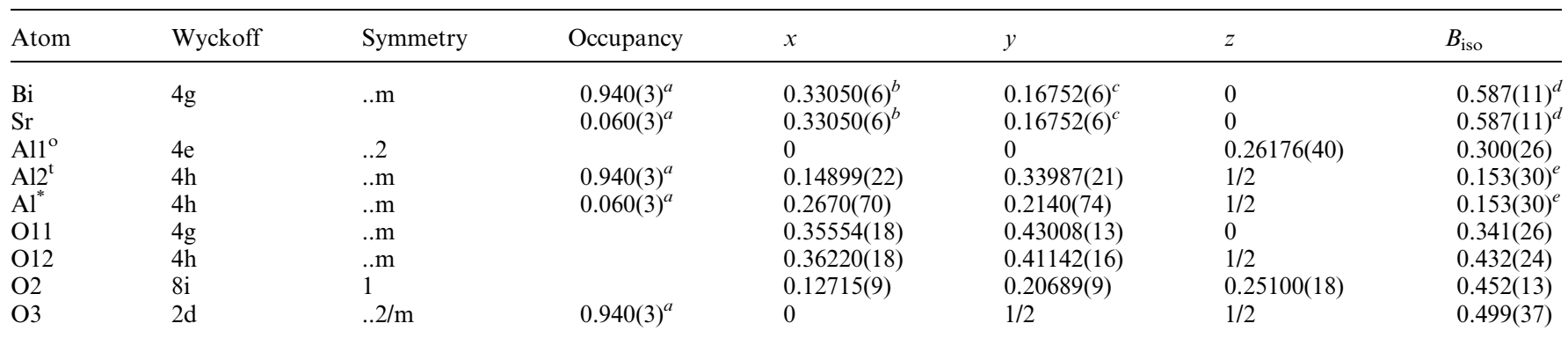

${ }^{a}$ Values with the same letters are constrained to each other. ${ }^{b}$ Values with the same letters are constrained to each other. ${ }^{c}$ Values with the same letters are constrained to each other. ${ }^{d}$ Values with the same letters are constrained to each other. ${ }^{e}$ Values with the same letters are constrained to each other.

other hand the fast synthesized sample, with more intrinsic defects, did not show any tri-cluster signal. It is a common observation that the isotropic chemical shift $\left(\delta_{\text {iso }}\right)$, quadrupolar coupling constant $\left(C_{\mathrm{Q}}\right)$ and asymmetry parameter $\left(\eta_{\mathrm{Q}}\right)$ of ${ }^{27} \mathrm{Al}$ 3MQ-MAS appear at values slightly different from those in the MAS NMR spectra (Table 2). The distorted $\mathrm{Al}^{*} \mathrm{O}_{4}$ sites associated with the tri-cluster oxygen defects give rise to a resonance at about $47 \mathrm{ppm}$, where there is an obvious mechanism of tri-cluster formation. In all three cases, due to its broad featureless characteristics the peak cannot be simulated to obtain unique values of $C_{\mathrm{Q}}$ and $\eta_{\mathrm{Q}}$, and thus its isotropic peak position with definite confidence. As a consequence, the tri-cluster $\mathrm{Al}^{*} \mathrm{O}_{4}$ species in pure $\mathrm{Bi}_{2} \mathrm{Al}_{4} \mathrm{O}_{9}$ and the normally synthesized strontium-doped samples cannot be resolved from the corresponding MAS NMR spectra due to its low intensity strongly overlapping (hidden) with the $\mathrm{AlO}_{4}$ species in the region of interest. Of course, setting constraint values (calculated from the 3QMAS signal) may help to simulate the MAS NMR signal; however, that will not provide any new results. The only possible interpretation of this feature is an average site with dispersed quadrupolar interaction parameters, which can be simulated using another model ('CzSimple' in 'dmfit'21 facilities, which is usually used for fitting relevant species in glasses). This 'CzSimple' model additionally provides the Gaussian distribution in the isotropic chemical shift dimension (F1), thus giving the Gaussian distribution of the quadrupolar coupling parameters (dispersion) and a subsequent summation of the computed weighted signal components (amorphous model). Nevertheless, a calculation of the total amount of triclusters out of these spectra was not possible.

\section{Neutron powder diffraction}

As a final proof for the incorporation of strontium into the structure, to confirm the tri-cluster formation and to describe the corresponding $\mathrm{Al}^{*}$ position, neutron powder diffraction data were collected. Out of two different measurements at room temperature carried out in a vanadium container and in a quartz tube stable at high temperatures, respectively, four different datasets were produced, representing two different measurements of one sample. A room temperature X-ray powder pattern was additionally used to increase the accuracy of the heavy atoms and their displacement parameters. Structure refinements using the Rietveld method were carried out using all five datasets simultaneously. As a starting model for these refinements positional parameters reported ${ }^{\mathbf{1 2}}$ for pure $\mathrm{Bi}_{2} \mathrm{Al}_{4} \mathrm{O}_{9}$ were used. From a crystal chemical point of view the strontium atoms incorporated in the structure could only replace bismuth atoms. This was confirmed by the chemical analysis carried out and therefore assumed to be correct. In the starting model this correlation was implemented as a linear constraint and 5 at $\%$ of bismuth were replaced by strontium. For charge balance, oxygen vacancies on oxygen position (O3) bridging two tetrahedra were additionally constrained as well as the corresponding aluminum on a tri-cluster position. Two corresponding tri-clusters are always formed when the $\mathrm{O} 3$ position is vacant. The applied constraints led to only one variable occupancy parameter during the refinements. The results of the refinements using the same displacement parameters for $\mathrm{A} 12 / \mathrm{Al}^{*}$ and $\mathrm{Bi} / \mathrm{Sr}$ are given in Table 3, selected corresponding interatomic distances in Table 4 and a Rietveld plot (with only one dataset for clarity) in Fig. 8. In the final refinement runs the strontium incorporation was calculated to be $6.0(3) \%$. This correlates well with the values found in the chemical analysis. On the other hand this value means that the aluminum tri-cluster position is also only occupied by $6.0(3) \%$ which makes it difficult to refine. Besides the fact that the $\mathrm{Al}^{*}$ position is plausible, the large estimated standard deviations on the positional parameters clearly show that the refined position (Fig. 9) and the corresponding Al-O distances should not be overinterpreted. Actually, one would also expect a split of the $\mathrm{O} 3$ position moving towards the $\mathrm{Al}^{*}$ position to shorten the $\mathrm{Al}^{*}-\mathrm{O} 3$ distances as observed in mullite.

Table 4 Interatomic metal-oxygen distances in $\left(\mathrm{Bi}_{0.94(1)} \mathrm{Sr}_{0.06(1)}\right)_{2} \mathrm{Al}_{4} \mathrm{O}_{8.94(1)}$. All distances shorter than $299 \mathrm{pm}$ for $\mathrm{Bi}$ and $270 \mathrm{pm}$ for $\mathrm{Al}$ are listed

\begin{tabular}{llll}
\hline $\mathrm{Bi} / \mathrm{Sr}$ & $1 x$ & $\mathrm{O} 11$ & $214.09(12) \mathrm{pm}$ \\
& $2 x$ & $\mathrm{O} 2$ & $214.81(9) \mathrm{pm}$ \\
& $1 x$ & $\mathrm{O} 11$ & $240.45(13) \mathrm{pm}$ \\
& $2 x$ & $\mathrm{O} 2$ & $288.68(9) \mathrm{pm}$ \\
$\mathrm{A} 11$ & $2 x$ & $\mathrm{~A}{ }^{*}$ & $291.59(120) \mathrm{pm}$ \\
& $2 x$ & $\mathrm{O} 12$ & $186.90(19) \mathrm{pm}$ \\
& $2 x$ & $\mathrm{O} 2$ & $194.69(18) \mathrm{pm}$ \\
$\mathrm{A} 12$ & $2 x$ & $\mathrm{O} 11$ & $194.74(19) \mathrm{pm}$ \\
& $1 x$ & $\mathrm{O} 3$ & $173.63(17) \mathrm{pm}$ \\
& $1 x$ & $\mathrm{O} 12$ & $174.59(22) \mathrm{pm}$ \\
$\mathrm{Al} *$ & $2 x$ & $\mathrm{O} 2$ & $179.12(14) \mathrm{pm}$ \\
& $1 x$ & $\mathrm{O} 12$ & $176.4(59) \mathrm{pm}$ \\
& $2 x$ & $\mathrm{O} 2$ & $178.4(33) \mathrm{pm}$ \\
& $1 x$ & $\mathrm{O} 3$ & $250.1(57) \mathrm{pm}$ \\
& $1 x$ & $\mathrm{O} 12$ & $265.2(59) \mathrm{pm}$ \\
\hline
\end{tabular}




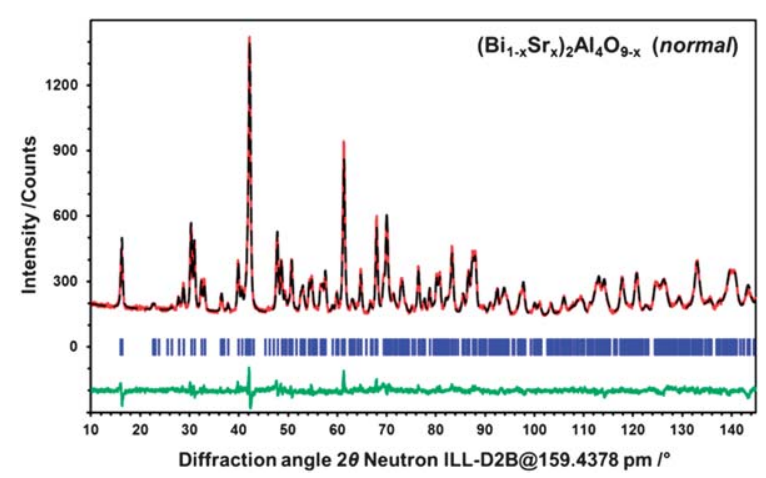

Fig. 8 Rietveld plot of powder neutron diffraction data refinement results collected at $298 \mathrm{~K}$ on a $\left(\mathrm{Bi}_{1-x} \mathrm{Sr}_{x}\right)_{2} \mathrm{Al}_{4} \mathrm{O}_{9-x}$ normally synthesized sample. This is one diagram out of five simultaneous refinements representing the high resolution data collected in a vanadium vessel. The observed (solid line) and calculated (interrupted line) intensities together with the positions of possible reflections (tick marks) and the difference curve between observed and calculated data (lower line) are given.

Nevertheless, an indication for this behavior could hardly be found within this occupation, except probably the slightly higher displacement parameter of the $\mathrm{O} 3$ atoms with respect to $\mathrm{O} 11$,

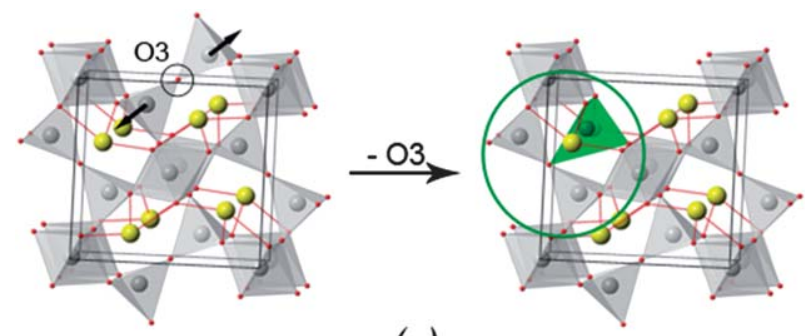

(a)

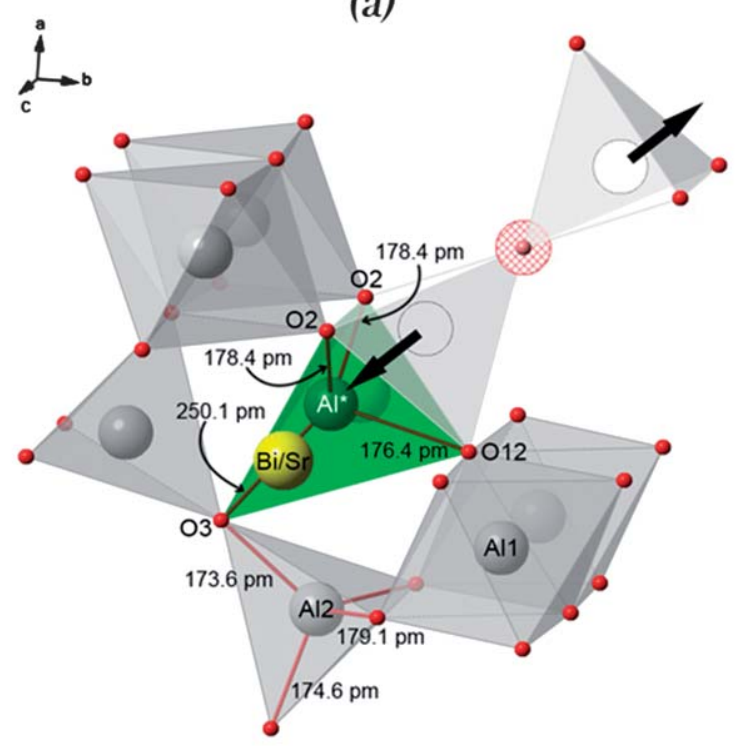

(b)

Fig. 9 (a) A mullite-type $\left(\mathrm{Bi}_{1-x} \mathrm{Sr}_{x}\right)_{2} \mathrm{Al}_{4} \mathrm{O}_{9-x}$ unit cell showing the $\mathrm{O} 3$ position (marked by the black circle) which is expected to be removed upon Sr-doping causing a shift (black arrows) of the $\mathrm{Al}$ atoms to the $\mathrm{Al}^{*}$ positions forming the tri-clusters. The resulting third tetrahedron is depicted in green. (b) The aluminum arrangement in the mullite-type tricluster indicating the atomic distances as determined by neutron powder diffraction.
$\mathrm{O} 12$ and $\mathrm{O} 2$. On the other hand $\mathrm{O} 3$ is the only oxygen atom which did not belong to $\mathrm{AlO}_{6}$ octahedra.

\section{DFT calculations}

The calculated charge densities for $\mathrm{Bi}_{2} \mathrm{Al}_{4} \mathrm{O}_{9}$ in space group Pbam show that the bismuth LEPs are clearly oriented and stereochemically active (see Fig. 1c and d). The charge densities at a plane parallel to the $c$-axis containing the bismuth atoms which alternate with the $\mathrm{Al}_{2} \mathrm{O}_{7}$ double tetrahedral units show both corresponding LEPs pointing to each other. The space free of dense electronic charge is narrow. Despite the fact that the calculated volume of the cell is slightly smaller than the experimental values (optimized lattice parameters for $P$ bam $\mathrm{Bi}_{2} \mathrm{Al}_{4} \mathrm{O}_{9}$ at $0 \mathrm{~K}$ are 768.99 $\mathrm{pm}, 809.72 \mathrm{pm}$, and $569.63 \mathrm{pm}$ for $a, b$, and $c$, respectively) due to the electronic space occupancy of the LEPs, the oxygen conductivity mechanism as proposed by Abrahams et al. ${ }^{8}$ and allegedly found by Zha et al. ${ }^{11}$ is unlikely in these systems.

\section{Conclusions}

The present study on mullite-type $\left(\mathrm{Bi}_{1-x} \mathrm{Sr}_{x}\right)_{2} \mathrm{Al}_{4} \mathrm{O}_{9-x}$ demonstrates that the phase can exist for $0.06 \leq x$. Since the amount of strontium differs between the initial feed (nominal) and the crystal structure, the reported ${ }^{11}$ strontium amount in the materials and the associated high conductivity left some open questions. Moreover, our investigation clarified that the thermal stability of $\left(\mathrm{Bi}_{1-x} \mathrm{Sr}_{x}\right)_{2} \mathrm{Al}_{4} \mathrm{O}_{9-x}$ is much lower than the temperatures used for the reported synthesis. ${ }^{11}$ Therefore, the earlier proposed conductivity ${ }^{11}$ may not cause to happen from the pure mullite-type phase as suggested by Ohmann et al. ${ }^{10}$ Both TEM and XPS confirmed the incorporation of strontium into $\left(\mathrm{Bi}_{1-x} \mathrm{Sr}_{x}\right)_{2} \mathrm{Al}_{4} \mathrm{O}_{9-x}$. The termination of the surface with aluminum was observed to be more pronounced in the doped sample than in the undoped one. Such a behavior imposes higher strain to the average crystal structure when bismuth is replaced by strontium. Moreover, this effect leads to a higher strontium exsolution in the surface of the materials produced by the normal glycerin method. The replacement of bismuth by strontium creates vacancies at specified sites of oxygen that bridge two tetrahedra $\left(\mathrm{Al}_{2} \mathrm{O}_{7}\right)$. The under-occupation of those oxygen sites was revealed during the combined crystal structure refinement from neutron and X-ray powder data. As a consequence, $\mathrm{Al}^{*} \mathrm{O}_{4}$ tri-clusters formed, and were confirmed by multi-quantum ${ }^{27} \mathrm{Al}$ MAS NMR. The DFT calculations showed the orientation of the stereochemically active lone electron pairs of $\mathrm{Bi}^{3+}$ cation. We propose a reliable alternative for the thermal behavior of $\left(\mathrm{Bi}_{1-x} \mathrm{Sr}_{x}\right)_{2} \mathrm{Al}_{4} \mathrm{O}_{9-x}$ within the investigated temperatures. A large number of intrinsic defects may originate due to fast synthesis, leading to even a higher distorted coordination of bismuth. Therefore, some $\mathrm{Bi}-\mathrm{O}$ bond distances may shorten for local charge compensation, resulting in an increased average binding energy of $\mathrm{Bi}^{3+}$ cations.

\section{Acknowledgements}

We gratefully acknowledge the Deutsche Forschungs gemeinschaft (DFG) for the financial support for the project GE1981/2-1 and FI442/14-1 within PAK 279. TMG would especially like to thank the DFG for support in the Heisenberg 
program (GE1981/3-1) and the mullite-LEP project GE1981/4-1. Thanks also to PD Dr Michael Fechtelkord (Ruhr-Universität Bochum, Germany) for the NMR data collection and Scott King and John V. Hanna (University of Warwich, Great Britain) for NMR measurements and fruitful discussions. CBM and MC gratefully acknowledge Consejo Nacional de Investigaciones Científicas y Técnicas (CONICET, Argentina). Finally we are very grateful to Isaac Abrahams (Queen Mary University London, Great Britain) for valuable comments on this paper.

\section{Notes and references}

1 J. B. Goodenough, Annu. Rev. Mater. Res., 2003, 33, 91-128.

2 T. Takahashi, H. Iwahara and T. Arao, J. Appl. Electrochem., 1975, 5, 187-195.

3 F. Abraham, M. F. Debreuille-Gresse, G. Mairesse and G. Nowogrocki, Solid State Ionics, 1988, 28-30, 529-532.

4 I. Bloom, M. C. Hash, J. P. Zebrowski, K. M. Myles and M. Krumpelt, Solid State Ionics, 1992, 53-56, 739-747.

5 H. K. Müller-Buschbaum and D. Charles de Beaulieu, Z. Naturforsch., 1978, 33b, 669-670.

6 A. G. Tutov and V. N. Markin, Izv. Akad. Nauk SSSR, Neorg. Mater., 1970, 6, 2014-2017.

7 R. X. Fischer, H. Schneider, The Mullite-Type Family of Crystal Structures, ed. H. Schneider and S. Komarneni, Mullite Wiley-VCH Weinheim, 2005, vol. 1-46, 128-140.
8 I. Abrahams, A. J. Bush, G. E. Hawkes and T. Nunes, J. Solid State Chem., 1999, 147, 631-636.

9 S. Larose and S. A. Akbar, J. Solid State Electrochem., 2006, 10, 488498.

10 S. Ohmann, P. Fielitz, L. Dörrer, G. Borchardt, Th. M. Gesing, R. X. Fischer, C. H. Rüscher, J.-Ch. Buhl, K.-D. Becker and H. Schneider, Solid State Ionics, 2012, 211, 46-50.

11 S. Zha, J. Cheng, Y. Liu, X. Liu and G. Meng, Solid State Ionics, 2003, 156, 197-200.

12 Th. M. Gesing, R. X. Fischer, M. Burianek, M. Mühlberg, T. Debnath, C. H. Rüscher, J. Ottinger, J.-Ch. Buhl and H. Schneider, J. Eur. Ceram. Soc., 2011, 31, 3055-3062.

13 G. S. Pawley, J. Appl. Crystallogr., 1981, 14, 357-361.

14 J. Bergmann, R. Kleeberg, A. Haase and B. Breidenstein, Mater. Sci. Forum, 2000, 347-349, 303-308.

15 R. Dovesi, R. Orlando, B. Civalleri, C. Roetti, V. R. Saunders and C. M. Zicovich-Wilson, Z. Kristallogr., 2005, 220, 571-573.

16 R. Dovesi, V. R. Saunders, C. Roetti, R. Orlando, C. M. ZicovichWilson, F. Pascale, B. Civalleri, K. Doll, N. M. Harrison, I. J. Bush, P. D'Arco, M. Llunell, CRYSTAL09 User's Manual, University of Torino, Torino, 2009.

17 J. P. Perdew, J. A. Chevary, S. H. Vosko, K. A. Jackson, M. R. Pederson, D. J. Singh and C. Fiolhais, Phys. Rev., 1992, B46, 6671-6687.

$18 \mathrm{http}: / /$ www.crystal.unito.it/Basis_Sets.

19 N. M. Sammes, G. A. Tompsett, H. Näfe and F. Aldinger, J. Eur. Ceram. Soc., 1999, 19, 1801-1826.

20 M. Pal, P. Brahma, D. Chakravorty, B. R. Chakraborty, C. Anandan and S. Bera, J. Mater. Sci. Lett., 1997, 16, 270-272.

21 D. Massiot, F. Fayon, M. Capron, I. King, S. Le Calvé, B. Alonso, J. O. Durand, B. Bujoli, Z. Gan and G. Hoatson, Magn. Reson. Chem., 2002, 40, 70-78. 